Historic, Archive Document

Do not assume content reflects current

scientific knowledge, policies, or practices. 



\subsection{2 \\ I 2 R3 1}

\section{COSTS OF LOGGING VIRGIN PONDEROSA PINE IN CENTRAL IDAHO}

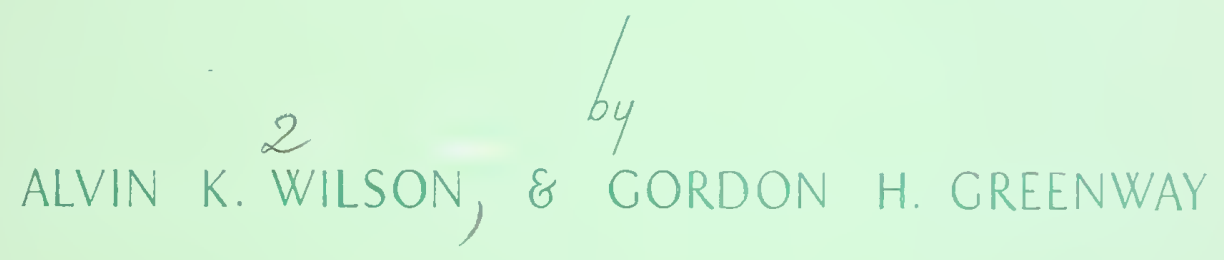

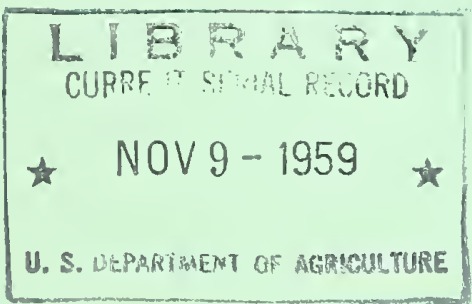

INTERMOUNTAIN FOREST \& RANCE EXPERIMENT STATION FOREST SERVICE

U. S. DEPARTMENT OF AGRICULTURE

OGDEN. UTAH

REED W. BAILEY. DIRECTOR 
United States

Department of

Agriculture

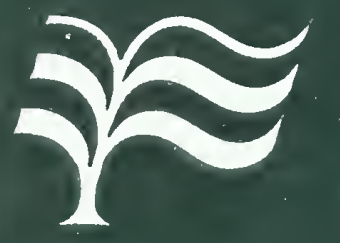

National Agricultural LIBRARY

Advancing Access to Clobal Information for Agriculture 


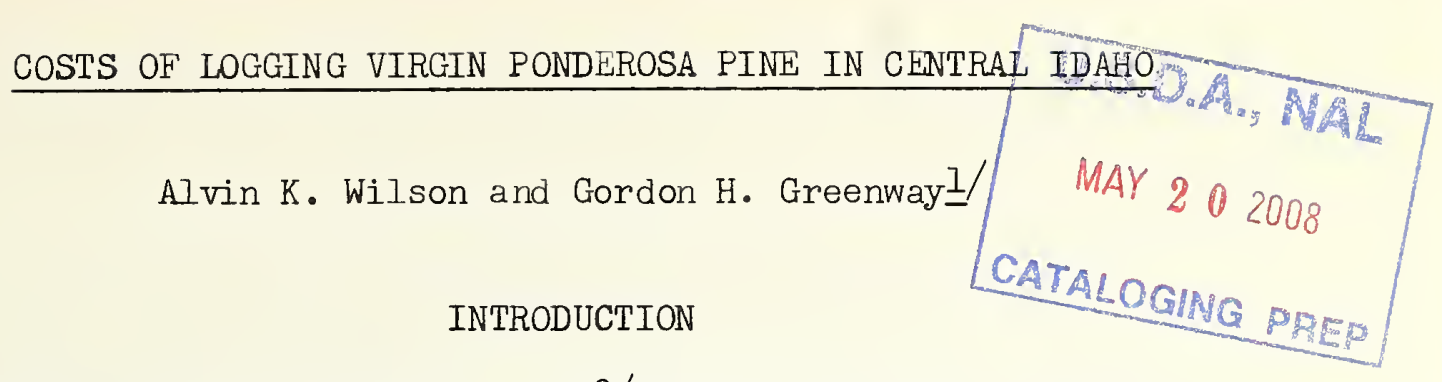

The installation of an experiment 2 /on the Boise Basin Experimental Forest 3 /near Idaho City, Idaho, during 1953 and 1954 afforded an opportunity to study the costs of logging virgin ponderosa pine. Production rates and costs for several phases of logging, as influenced by initial stand per acre, intensity of cut, and sizes of skidding equipment under two timber marking methods were collected and analyzed. Provisions for the collection of data for such an analysis were written into the timber sale contract with the Boise Payette Lumber Company, which in turn delegated the task to their operator, the MacGregor Triangle Company.

While many aspects of the logging operation study will be of interest mainly to logging contractors, the analysis of data concerning skidding equipment should also be useful to forest land administrators, especially when considered in conjunction with prospective damage to reproduction and watersheds. These effects as related to skidding machinery size were incorporated in the over-all study and results will be published in later papers.

The study areas were in the virgin ponderosa pine type at elevations between 4,600 and 5,800 feet above sea level. The topography is dissected by many intermittent watercourses, and steep slopes to a maxima of 84 percent are often encountered. The soil is granitic, sandy, and very erosive.

Logging roads were located prior to the sale and were kept, with very few exceptions, to grades of 8 percent or less. They followed watercourses for the most part, with particular attention given to preserving a 10-foot strip of undisturbed vegetation between the drainage bottom and the toe of the road overspill.

I/ Foresters, Intermountain Forest and Range Experiment Station, Forest Service, and MacGregor Triangle Company, Boise, Idaho, respectively.

2/ Curtis, James D. 1955. A study of ponderosa pine production in centră Idaho. Intermountain Forest and Range Expt. Sta. Misc. Pub. 4, 9 pp., illus.

3/ Maintained by the Intermountain Forest and Range Experiment Station, U. S. Forest Service, Ogden, Utah. 
A total of 4,902 M board feet, gross saw scale, $4 /$ was cut within study areas to produce a net log scale of 4,201 $\mathrm{M}$ b.f. The average cut for the whole operation amounted to 35.5 percent of the gross initial volume.

The conditions under which the logging operation on the experimental forest was carried out differ only in minor respects from those encountered in current national forest sales in central Idaho. The experimental forest is more easily reached by road than most of the virgin ponderosa pine now being logged. Differences attributable to accessibility would influence only the equipment mobilization and trucking costs. The high degree of supervisory control over the operation was exceptional but necessary to insure successful installation of the timber management study. Except for these differences, the study area provided typical conditions for a logging operation in central Idaho.

\section{EXPERIMENTAL DESIGN}

Sixteen compartments, totaling 847 acres and ranging in size from 32 to 79 acres, were used in the study. Each compartment was a minor drainage of the principal stream flowing through the experimental forest and could be considered as a small, independent logging unit. Within each compartment the boundaries between areas of light timber (less than $10 \mathrm{M}$ b.f. per acre), medium timber ( 10 to $20 \mathrm{M} \mathrm{b.f.} \mathrm{per} \mathrm{acre),} \mathrm{and} \mathrm{heavy}$ timber (over $20 \mathrm{M} \mathrm{b.f.} \mathrm{per} \mathrm{acre),} \mathrm{had} \mathrm{been} \mathrm{marked} \mathrm{and} \mathrm{mapped.} \mathrm{Eight} \mathrm{com-}$ partments were logged in the fall and early winter of 1953 and the remaining eight, which contained the same treatment combinations as the first eight, were logged in the fall and early winter of 1954. The treatments applied, including the size of tractor to be used for skidding, were assigned without bias. For the eight compartments logged in either of the two years of operation, the combinations of treatments were as follows:

\begin{tabular}{|c|c|c|c|}
\hline & $\begin{array}{l}\text { Skidding } \\
\text { equipment }\end{array}$ & $\begin{array}{c}\text { Timber marking } \\
\text { method }\end{array}$ & $\begin{array}{l}\text { Reserve } \\
\text { volume I }\end{array}$ \\
\hline Large & tractor $(D-8)$ & Stem selection & High \\
\hline 18 & $"$ & $\|$ & Low \\
\hline$"$ & $" 1$ & Group selection & High \\
\hline it & $" 1$ & " 11 & Low \\
\hline Small & tractor $(D-4)$ & Stem selection & High \\
\hline$" 1$ & 11 & 1111 & Low \\
\hline$" 1$ & "1 & Group selection & High \\
\hline$" 1$ & 11 & 1111 & Low \\
\hline
\end{tabular}

\footnotetext{
4/ Log scale before skidding by Scribner Rule, including long butts, cutouts for breaks, snag volumes, and underrun due to hidden breaks and defect.
} 
The selection of two tractor sizes (fig. I) for inclusion in the experiment was prompted by consideration of timber stand damage and watershed damage as well as by the desire to compare their efficiency of operation in the timber and topography of this area. The large tractor is the size commonly used in ponderosa pine operations in Idaho. The small tractor was considered to be the least powerful tractor that could operate successfully under typical conditions. Tractor skidding without pans or arches is typical of most logging in this part of Idaho.

Stem selection as applied here is a timber marking system in which each merchantable tree is appraised as to its probability of dying before logging operations reach the area again. Trees with the highest mortality probability (high-risk trees) are marked for cutting. The implications of this system to the logger are:

1. Since the age or maturity of a tree is considered in the appraisal of its mortality probability, the oldest trees generally rate higher risk classifications. This in turn means that the largest trees are more certain to be cut than smaller, younger trees, and the average volume per cut tree tends to be high and the number of logs per $M$ b.f. low. The effect would be to lower production costs since large logs are generally cheaper to handle.

2. Since stem selection is on an individual tree basis, the marked trees are usually well scattered over an area although they may occur occasionally as small groups. Skidding logs from trees distributed in this way requires numerous skid trails reaching into all parts of the area. Thus it can be expected that more skidding time per turn of logs is required than where logs are concentrated as they are in group clearcuttings. Felling and bucking production rates might also be lower with scattered trees, due to "deadhead" time finding trees and moving equipment, than where group clearcuttings are made.

Technically, group selection is a regeneration method, although it is referred to in this analysis as a marking system. Under this system groups of overmature and mature overstory trees up to an acre in size are removed by clearcutting to create openings for reseeding or planting or to free established pole or seedling-sapling stands. Wherever reserve levels permitted, single scattered high-risk trees also were removed from area between the group cuttings. "Unit Area Control," $5 /$ as currently practiced in California and Oregon, includes many of the management concepts of the group selection system applied to half of the compartments of this study. The implications of the method to the logger are:

5/ Hallin, William E. 1954. Unit area control--its development and application. California Forest and Range Expt. Sta. Misc. Paper 16, $10 \mathrm{pp}$. 


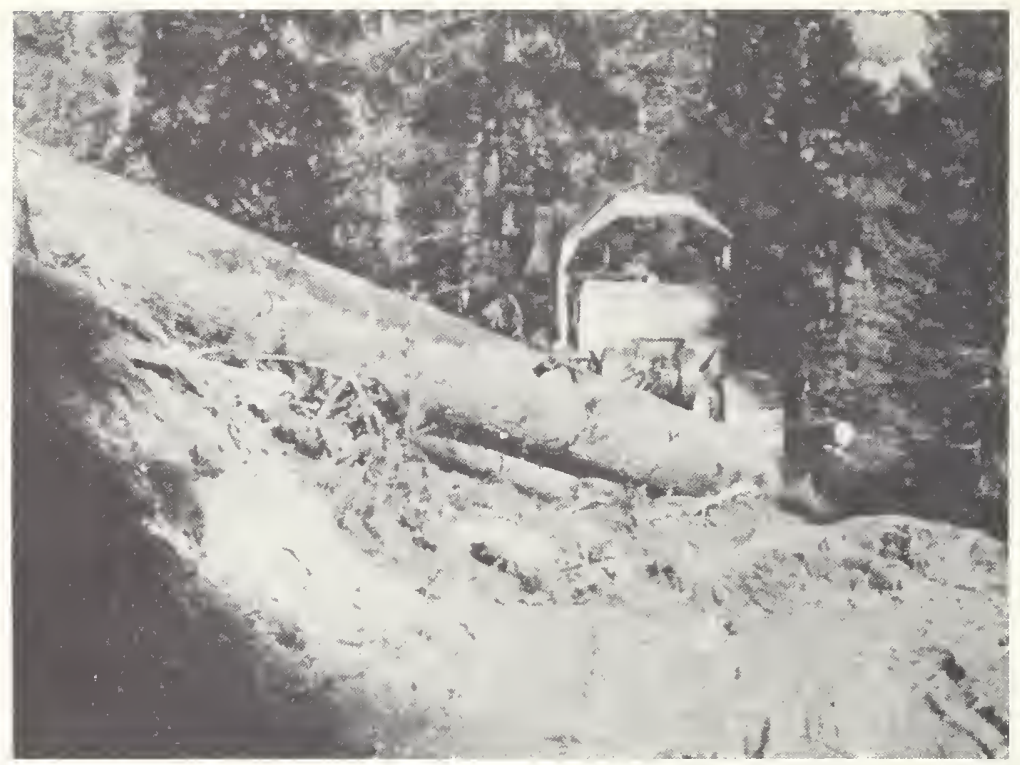

A.

Figure 1.--The large (A) and small (B) tractors operating on the Experimental Forest, showing the size of timber, the topography, and the decking arms with which each tractor was equipped.

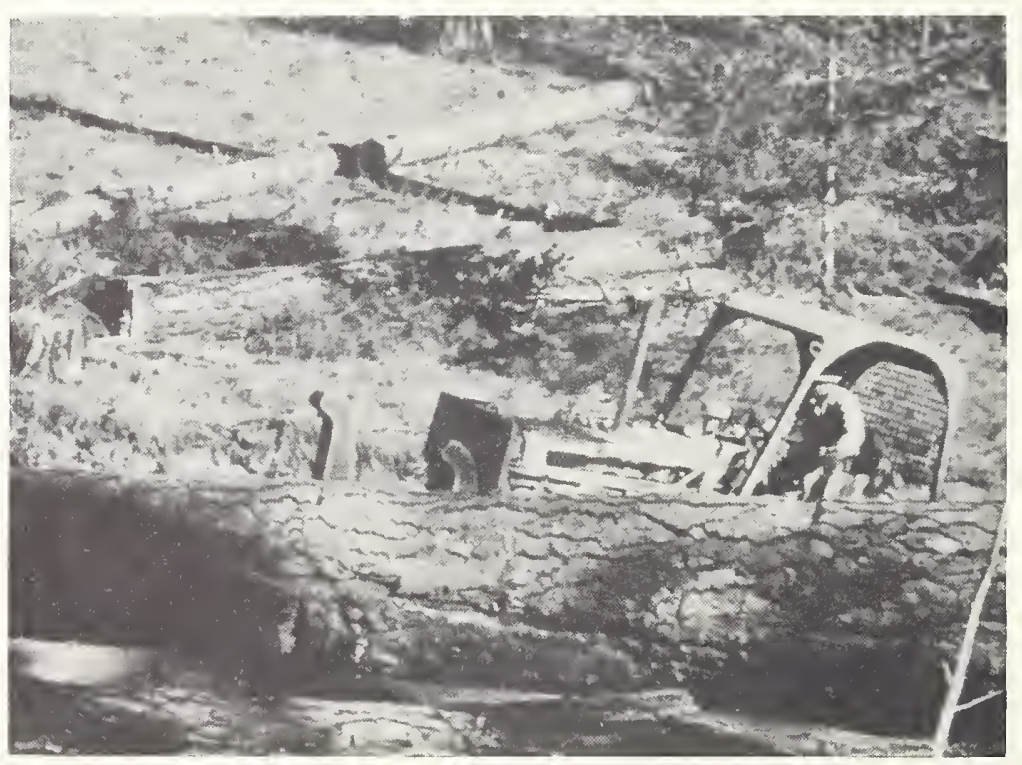

B. 
1. Felling, bucking, and skidding activity are confined to relatively small areas within each compartment, leading one to expect that, compared with stem selection, "deadhead" time for fallers would be reduced and their production rates raised accordingly. Skidding production might tend to be greater with high concentrations of logs.

2. For effective application, group selection requires that all sawtimber trees be cut on the designated areas. Thus, even though stands of overmature trees are given highest priority for cutting, it is typical that an appreciable number of small, immature trees must be cut along with them, resulting in more logs per $\mathrm{M}$ b.f. than where the removal of large mature and overmature trees is emphasized as in stem selection. The influence of the concentration of logs by group cutting on production $r$ ates would be counteracted to some extent by the larger number of logs per M b.f.

Within the general "high" and "low" levels for reserve stand volumes, predetermined volumes per acre to be retained were set up for each of the light, medium, and heavy timber class areas. All sawtree volume over these reserve volumes was removed. A "high" reserve level generally meant a low percentage cut, and a "low" reserve level meant a higher percentage cut.

Table 1 illustrates the average stand volumes which were present before cutting and the cutting intensities applied to arrive at the desired reserve volumes. It also gives some idea of the range in sizes of cut trees.

Note that cut trees averaged definitely larger for stem selection marking than for group selection marking, and that low reserve volumes resulted in cutting intensities ranging from 32 to 50 percent, averaging over 40 percent, while high reserve volumes required cuts of 22 to 32 percent, averaging less than 30 percent.

Man hours, machine hours, and volumes of logs produced were recorded for each timber volume class area of each compartment for the felling and bucking, scaling, and skidding phases. Loading and trucking man-hours and hours of equipment use were not broken down by compartments or volume classes, but were presented as totals for each season's operation.

Fallers worked individually, using l-man chain saws and axes to fell, limb, and buck. Limbing was done on the three most accessible of the four "faces" of the felled tree; the remaining limbs and broken stubs were trimmed off at the landing. Wherever possible, uphill and downhill felling was practiced to minimize the damage to the residual stand caused by rolling trees and logs. This practice also placed the logs in a more efficient and safe position for "direct-line" skidding. Where group clearcuttings were made, trees were felled into the clearcutting area to confine the area of stand damage. All snags at least 12 inches d.b.h. and 10 feet in height were cut in the felling operation; these were paid for on the basis of the volume of the 16-foot butt log. Wherever possible 


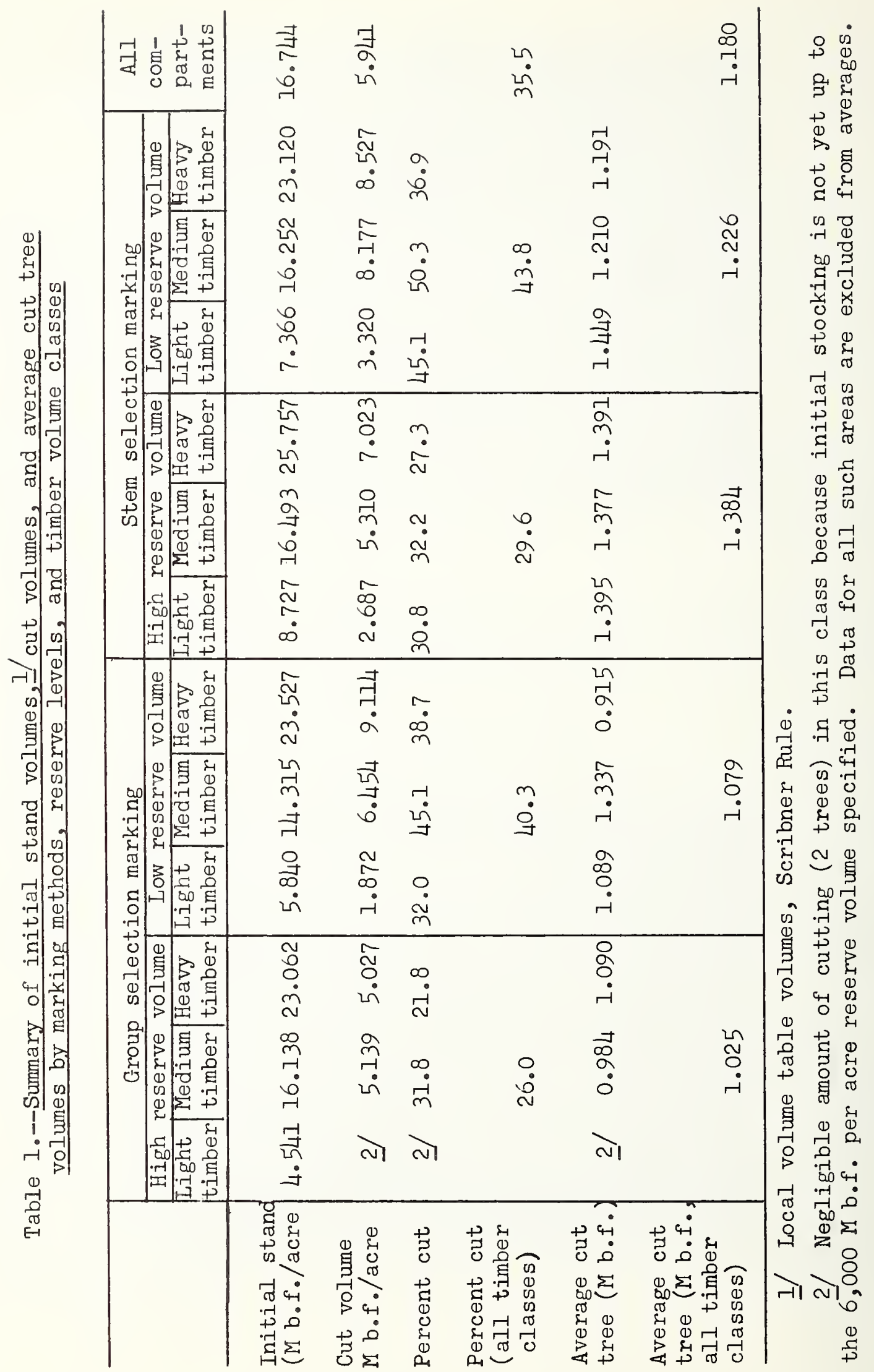


32-foot logs were cut. However, due to the overmaturity of most of the timber, considerable breakage occurred and logs to an 8-foot minimum length were taken from the woods.

Tractor operators were instructed to avoid, within reason, any damage to standing trees of all sizes; "siwashing" of logs around trees was to be avoided and reasonable precautions were to be taken where there was danger of barking reserve sawtrees. To minimize soil erosion, skid trails followed ridges as much as possible and the same skid trail was used as often as possible. This served to concentrate the unavoidable damage to reproduction and to localize and reduce soil rehabilitation work. Skiding down draw bottoms was to be avoided at all costs; draws were to be crossed at right angles only. Where contour skidding was necessary, bladed skid trails were prepared. No dozer blades were permitted on the tractors during skidding; blades were replaced by specially designed decking arms (see figure 1 ).

Logs were skidded in practically all cases to landings located within the light, medium, or heavy timber class area being worked. In only a few cases was it necessary to skid logs from one timber class area to a landing located in a different timber class area. Production rates could therefore be kept separately for each timber class of each compartment.

Before beginning work on the sale, fallers and tractor operators were given pocket-size booklets which briefly described the experiment, set forth felling and skidding practices to be observed, and enlisted their cooperation in completing the installation according to plan. Compartment maps which showed the locations of marked trees and timber class boundaries were also furnished.

Close supervision of all phases of the operation was possible wi th the combined efforts of foresters representing research, National Forest Administration, the contracting lumber company, and the logging company; one or more of these foresters was on the sale area at all times. Supervision alone cannot be given full credit for the successful installation of the experiment; much of it is due to the keen interest taken by the fallers, equipment operators, and others on the job.

Neither topography, weather, road layout, nor sale terms imposed unusual or atypical conditions for an operation in this part of Idaho, so that production rates as related to timber class, intensity of cut, marking methods, and average cut tree sizes were expected to furnish reasonable estimates of actual rates obtainable elsewhere in central Idaho. 


\section{RESULTS}

Readers with a bent toward statistics will appreciate that the Ponderosa Pine Production Study was designed particularly for the use of "analysis of variance" techniques,6/which were applied to several aspects of the felling and bucking, and skidding phases of the operation. Detailed analyses were applied only to data from the medium and heavy timber classes, because several areas of light timber were understocked and afforded no logging data.

\section{Felling and Bucking}

Since fallers are paid on a per thousand board feet basis (gross saw scale) dollar costs per thousand board feet are of less interest than log production rates because pay scales are determined by negotiation between union representatives and contractors. Accordingly, production rates (board feet per man-hour) for felling and bucking were analyzed to determine the effect of year of logging (1953 or 1954), marking method, reserve volume levels, timber volume classes, and all the interactions of these factors on them.

Of all these elements, only the marking method--reserve volume level interaction proved significant at the 95 percent confidence level. Further examination showed that the highest production rates occurred with stem selection marking and a high level of reserve volume while the lowest production rates were found where group clearcutting at a high-reserve level was practiced. Intermediate production rates were found under both marking systems where low reserve volumes were retained (table 2).

Table 2.--Felling and bucking production rates (M board feet per man-hour) by marking methods and reserve volume levels 1 f

\begin{tabular}{c|c|c}
\hline \multirow{2}{*}{$\begin{array}{c}\text { Reserve volume } \\
\text { level }\end{array}$} & \multicolumn{2}{|c}{ Marking method } \\
\cline { 2 - 3 } & Group selection & Stem selection \\
\hline High & $\frac{\text { M bd.ft. }}{2.216}$ & $\frac{\text { M bd. ft. }}{2.866}$ \\
Low & 2.666 & 2.464 \\
\hline
\end{tabular}

If Data from medium and heavy timber classes only.

This arrangement of production rates could not be explained satisfactorily by relating them to cutting intensities since the volume class-reserve level interaction, which can be considered an expression of intensity of cut, was not significant. The inference can be drawn that nonproductive time was little affected by the conditions of the study.

6/ Snedecor, George W. 1946. Statistical methods. 4th Ed. $485 \mathrm{pp}$. 
An explanation for the differences in production rates was found when the same analysis techniques were applied to cut tree sizes. Again, the only significant factor found was the interaction of marking method and reserve level. Cut trees averaged largest for stem selection--high reserve, lowest for group selection--high reserve, and intermediate for low reserves under both marking methods.

Since average sizes of cut trees paralleled the felling and bucking production rates for the four marking method--reserve level combinations, a regression equation for predicting production rates from average cut tree sizes was derived from pooled data by the method of least squares. The relationship was highly significant and took the form

$$
Y=1.49+0.86 \mathrm{X}
$$

where $\mathrm{Y}$ is the felling and bucking production rate in $\mathrm{M} \mathrm{b}$. $\mathrm{f}$. per hour and $X$ is the volume (in $M$ board feet) of the average cut tree. It appears in graphic form in figure 2 .

The results obtained here are in agreement with Hasel's / conclusion regarding logging output rates in Califormia ponderosa pine stands: differences in cost (meaning output rather than dollar costs) are due almost entirely to tree-size makeup of stands marked rather than to intensity of cutting.

\section{Tractor Skidding}

Production Rates

Analysis of tractor skidding tested the effects of the same factors and combinations of factors on skidding production rates as were tested for felling and bucking.

The large tractor, as expected, showed the higher average production rate for the operation ( $5.805 \mathrm{M} \mathrm{b.f.} \mathrm{per} \mathrm{hour} \mathrm{as} \mathrm{compared} \mathrm{to} 3.985 \mathrm{M} \mathrm{b}$. f. per hour for the small tractor), and maintained the higher rate despite its average skidding distance, as estimated from skid trail lengths (274 feet as compared to 208 feet for the small tractor).

The only other significant effect was the combination of timber class and reserve volume, which has been previously suggested to be an approximation of cutting intensity. Production rates for both tractors were highest in heavy timber cut to a high reserve $8 /$ (table 3 ) but conflicting output rates occur for all other timber class--reserve ccmbinations.

1/ Hase1, A. A. 1946. Logging cost as related to tree size and intensity of cutting in ponderosa pine. Jour. Forestry 44: 552-560 8/ A comparatively light cut: 22 to 27 percent, table 1 data. 


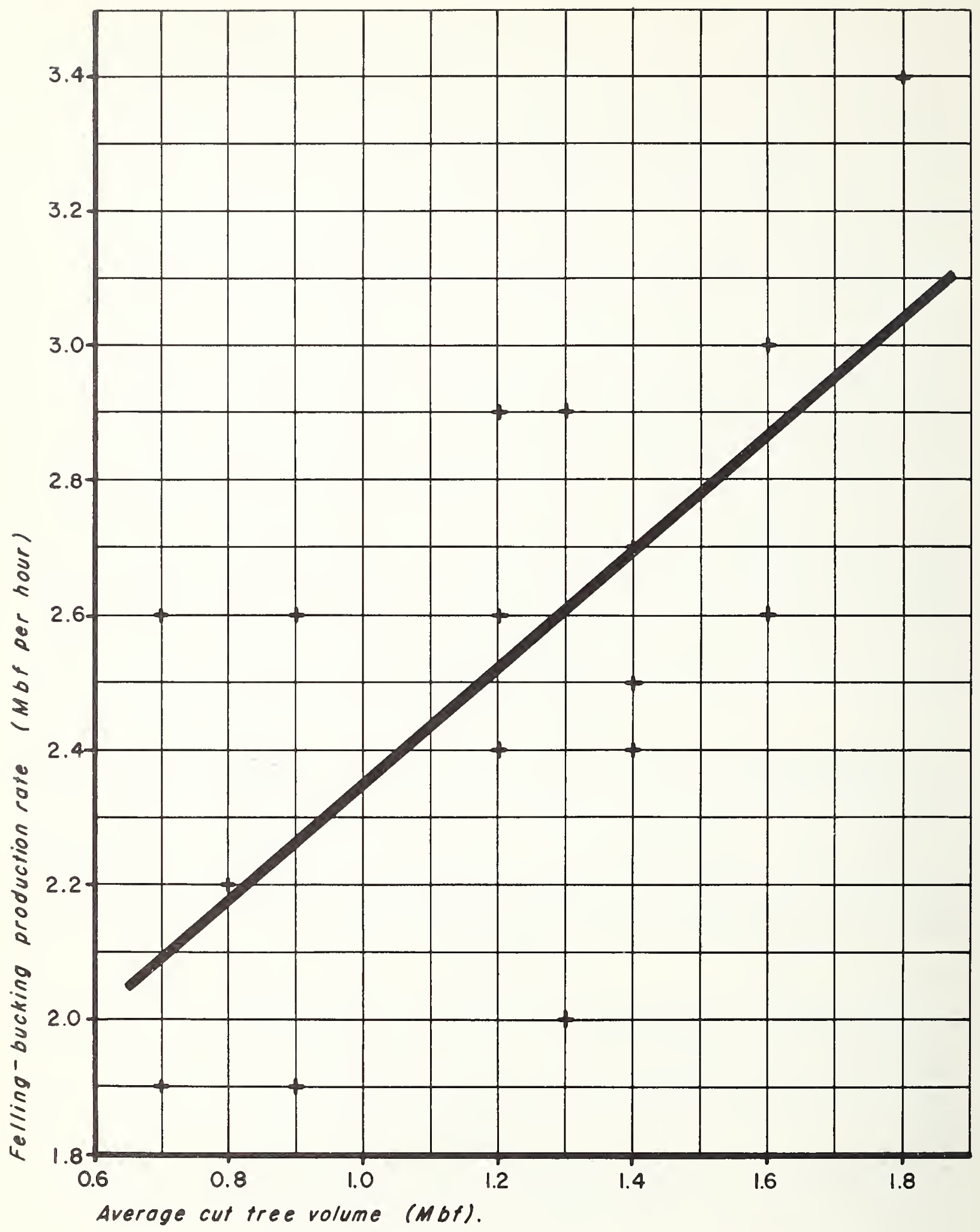

Figure 2. Felling-bucking production rates as influenced by average cut tree size. 
Table 3.--Skidding tractor production rates ( $M$ b.f. per tractorhour) by timber classes and reserve levels

\begin{tabular}{|c|c|c|c|c|c|}
\hline \multirow{2}{*}{$\begin{array}{c}\text { Reserve } \\
\text { volume } \\
\text { level }\end{array}$} & \multicolumn{2}{|c|}{ Small tractor } & \multicolumn{3}{|c|}{ Large troctor } \\
\hline & Medium timber & Heavy timber & Mediu & timber & Heavy timber \\
\hline & M b.f.per hour & M b.f.per hour & Mb.f. & er hour & Mb.f.per hour \\
\hline $\begin{array}{l}\text { High } \\
\text { Low }\end{array}$ & $\begin{array}{l}3.730 \\
4.371\end{array}$ & $\begin{array}{l}4.602 \\
3.240\end{array}$ & & $\begin{array}{l}5.718 \\
4.614\end{array}$ & $\begin{array}{l}7.696 \\
5.189\end{array}$ \\
\hline
\end{tabular}

A partial explanation of the highest production rates can be found in table 4 , which shows that skid trail lengths averaged less (especially for the large tractor) in heavy timber than in medium timber. This probably helped boost output where cutting was light but its effect cancelled where cutting became heavy enough to affect tractor maneuverability. Further analysis of this aspect was not considered warranted because of the unreliability of average skid trail lengths as estimates of average skidding distances.

Table 4.--Average skid trail lengths, by tractors, timber classes, and reserve levels

\begin{tabular}{c|cc|c|c}
\hline \multirow{2}{*}{$\begin{array}{c}\text { Reserve } \\
\text { volume } \\
\text { level }\end{array}$} & \multicolumn{2}{|c|}{ Small tractor } & \multicolumn{2}{c}{ Large tractor } \\
\cline { 2 - 5 } & Medium timber & Heavy timber & Medium timber & Heavy timber \\
\hline & $\underline{\text { Feet }}$ & $\underline{\text { Feet }}$ & $\underline{\text { Feet }}$ & Feet \\
High & 203 & 221 & 331 & 228 \\
Low & 223 & 186 & 294 & 236 \\
\hline
\end{tabular}

Regression analyses were made of the relationship between average cut tree size and skidding output rates, and intensity of cut as related to production. Neither analysis showed a trend definite enough to be considered significant. In these respects, the results obtained in this study differ from those obtained by Hasel (page 9) who found that yarding time for heavy cutting was less than for lighter cutting and that tree size was the most important factor entering into skidding output rates. These factors probably affect skidding output in Idaho ponderosa pine operations in much the same way as in California, but the linitations of the method of study, the irregular topography, and the great disparity of the capabilities of the two tractors tend to obscure the effects of tree size and cutting intensity. 
Had tree sizes averaged smaller, it is quite possible that the small tractor could have skidded as economically or even more eccnomically than the large tractor. As it was, the small tractor lost appreciable time handling big logs and had more maintenance problems than the large tractor. From the available data, 9 the small tractor's output cost per M b.f. was 1.03 times that of the large tractor.

On these bases, costs for the two tractors do not differ much, but further consideration is necessary. Despite the random assignment of treatments, more favorable road-building chances occurred in the small tractor compartments than in those selected for large tractor operation, with the result that more road per acre of operating area was constructed in these compartments. The amount of main haul road per unit of operating area was essentially the same for both tractors. This road construction has the effect of further reducing average skidding distances for the small tractor. Comparative costs of the two tractors should, therefore, take intc account the cost of the "excess" spur road in the small tractor compartments, which was computed as the difference between the actual length of spur road and that which wculd have been built if the "spur road length per acrell ratio of the large tractor compartments had been applied. When the cost of the computed "excess" road was included, it was found that small tractor skidding cost 1.43 times that of the large tractor.

However, the logging company was so impressed by the possibilities for using less powerful tractors than the large size that they have adopted a practice of using a medium tractor in combination with a large one for logging similar timber and report it a very satisfactory arrangement. The medium tractor is more powerful than the small tractor and, under ordinary circumstances, is faster than the large, but having the large tractor on the same job makes still more power available when difficulties arise.

\section{Loading and Trucking}

A Model 41 Ncrthwest loader was used for all loading. For the entire operation, 9.103 M b.f. were loaded per hour of equipment use.

Trucking involved a 72-mile highway haul plus 5 miles of woods roads, with adverse grade occurring only for about 2 miles of the highway. With average loads of $5.94 \mathrm{M}$ b.f., $0.888 \mathrm{M}$ b.f. were delivered to the mill per hour of equipment use.

9/ Includes equipment use cost, labor, and fuel, but only a very. small part of maintenance costs due to the company's practice of charging equipment maintenaice for all machines against the log camp rather than to individual machines. 
As a sidelight on an operation which is considered typical, with the minor exception noted of present national forest sales in southwestern and central Idaho, the distribution of logging costs are presented in two tables. Table 5 shows the man- and equipment-hours required to fell, skid, load, and truck a thousand board feet of logs. Except for the highly variable item of trucking, a logging contractor could obtain from these rates a reasonably good estimate of his own costs for a similar operation by employing his own hourly labor and equipment rates.

Table 5.--Man- and equipment-hours per thousand board feet (net $\log$ scale) $\stackrel{1}{=}$

\begin{tabular}{l|cc}
\hline & Labor items & Equipment items \\
\hline \multirow{2}{*}{$\begin{array}{c}\text { (Felling and bucking } \\
\text { Felling( Scaling }\end{array}$} & $\frac{\text { Man-hours }}{2 / 0.465}$ & Machine-hours \\
Skidding & .3 .15 & - \\
Loading & .878 & $3 / 0.218$ \\
Trucking & .455 & .110 \\
$\quad$ Totals & 1.136 & 1.126 \\
\hline
\end{tabular}

I/ Basis: 4,201.070 M b.f.

2/ Chain saw use and maintenance included in contract felling pay rates.

3) Average rate, small and large tractors. Separate rates are: small tractor, $0.252 \mathrm{hr} . / \mathrm{M} \mathrm{b.f.;} \mathrm{large,} 0.186 \mathrm{hr} . / \mathrm{M}$ b.f.

The following tabulation shows the actual dollar costs for this operation as percentages of the cost of logs delivered to the mill. The most variable items, mobilization, roads, and trucking (normally considered direct costs), have been shown separately in the tabulation. Percentagewise reapportionment of costs to exclude one or both of these variable items can be accomplished by subtracting them from 100 percent and recalculating the remaining items proportionally. 
Supplies and expense . . . . . . . . 3

Total ............ 10.5

Skidding

Labor . . . . . . . . . . . . . . . . . . . . . . . . . . 4.5
Equipment use 4.1

Supplies and expense . . . . . . . . . . . . 6

Loading

$$
\text { Total ........... . . . } 11.2
$$

Labor . . . . . . . . . . 3.9

Equipment use ......... . 2.6

Supplies and expense . . . . . . . . 6

Total ........... .

Variable direct costs

Mobilization .. . . . . . . . . . 1.4

Main logging road .. . . . . . . 3.3

Woods roads . . . . . . . . . . 10.3

Trucking

Total ............. . . . . 15.0

Labor . . . . . . . . . . . 9.1

Equipment use ......... . . 24.6

Supplies and expense . . . . . . 6.4

Total ...........

40.1

Indirect logging costs

Camp costs ... . . . . . . . . 2.5

General overhead expense . . . . . . . 9.7

Supervision ......... . . . 2.0

Employees' welfare . . . . . . . . 1.9

Total ........... 16.1

Total cost of logs delivered ........ 100.0 


\section{SUMMARY}

Installing an experiment designed primarily to test the silvicultural and watershed aspects of two logging methods, two marking methods, and two levels of reserve stand volume in the virgin ponderosa pine type on the Boise Experimental Forest, afforded an opportunity for obtaining data on logging costs as related to a number of variables. Conditions for the logging operation were, with few minor exceptions, typical of national forest sales in central Idaho.

Felling-bucking production rates were found to be highest where stemwise marking with a high level of reserved volume was practiced and lowest rates occurred where groupwise marking to a high reserved volume level was employed. A definite correlation existed between production rates and the size of the average "cut" tree. No other factors or combinations of factors were found to be significantly related to output rates.

For skidding production, the large tractor showed the highest rate, as expected. Both tractors produced at their highest rates in heavy timber stands which were cut to a high reserve volume (a relatively low intensity of cut). In other combinations of timber stands and levels of reserve volume, different patterns of output rates occurred for each tractor. Regressions of production rates over percentage cut and over average cut tree size showed no significant trends due, no doubt, to uncontrolled variation in the experiment. Analysis of dollar costs by tractors showed that the small tractor cost 1.43 times as much as the large tractor per thousand board feet skidded. On the whole, the trees averaged too large in size for economical operation of the small tractor.

Tables are presented to show the distribution of logging costs for a reasonably typical operation in two ways--in terms of man- and equipmenthours per thousand board feet and as percentages of the total cost of logs delivered to the mill. 


NATIONAL AGRICULTURAL LIBAARV

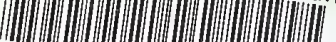
1022500778 